\title{
Edaphoclimatic factors determining sunflower yields spatiotemporal dynamics in northern Ukraine ${ }^{\text {th }}$
}

\author{
Anastasiia Zymaroieva ${ }^{1, *}$, Oleksandr Zhukov ${ }^{2}$, Tetiana Fedoniuk ${ }^{1}$, Tetyana Pinkina ${ }^{1}$ \\ and Volodymyr Vlasiuk ${ }^{1}$ \\ ${ }^{1}$ Polissia National University, Zhytomyr, Ukraine \\ 2 Bogdan Khmelnitsky Melitopol State Pedagogical University, Melitopol, Ukraine
}

Received 25 September 2020 - Accepted 11 March 2021

\begin{abstract}
The climate and soil conditions have a significant impact on sunflower yields. Sunflower yield dynamics in the Central European mixed forests (Polissya) and Eastern European forest-steppe ecoregions in Ukraine from 1991 to 2017 was proved to fit a log-logistic model most adequately. The model has four characteristic parameters: the Lower Limit indicates the lowest level of yield over the study period; the Slope indicates the rate of yield increase over time; the ED50 is the time required to reach half of the maximum yield level and simultaneously the point with the highest rate of yield increase; the Upper Limit shows the highest yield level. The parameters of the yield model are used to meaningfully interpret the causes of yield dynamics. Edaphoclimatic factors account for 34 to $58 \%$ of the variation in the yield trend parameters. The soil texture and soil organic carbon (SOC) predominate among the edaphic factors that determine the variability of sunflower yield. Continentality of climate and degree of temperature variability during the growing season are the main climatic determinants of sunflower yield parameters.
\end{abstract}

Keywords: sunflower / yield / trend / climate / soil conditions

\begin{abstract}
Résumé - Facteurs édaphoclimatiques déterminant la dynamique spatio-temporelle des rendements de tournesol dans le nord de l'Ukraine. Les conditions climatiques et pédologiques ont un impact significatif sur les rendements du tournesol. La dynamique du rendement du tournesol dans les écorégions de forêts mixtes d'Europe centrale (Polissya) et de forêts-steppes d'Europe orientale en Ukraine de 1991 à 2017 s'est avérée en adéquation avec un modèle log-logistique. Le modèle repose sur quatre paramètres caractéristiques : la limite inférieure indique le niveau de rendement le plus bas sur la période d'étude; la pente indique le taux d'augmentation du rendement dans le temps; l'ED50 est le temps nécessaire pour atteindre la moitié du niveau de rendement maximal et simultanément le point avec le taux d'augmentation du rendement le plus élevé; la limite supérieure indique le niveau de rendement le plus élevé. Les paramètres du modèle de rendement sont utilisés pour interpréter de manière significative les causes de la dynamique du rendement. Les facteurs édaphoclimatiques représentent 34 à $58 \%$ de la variation des paramètres de la tendance du rendement. La texture du sol et le carbone organique du sol (SOC) prédominent parmi les facteurs édaphiques qui déterminent la variabilité du rendement du tournesol. La continentalité du climat et le degré de variabilité de la température pendant la saison de croissance sont les principaux déterminants climatiques des paramètres de rendement du tournesol.
\end{abstract}

Mots clés : tournesol / rendement / tendance / climat / conditions pédologiques

\footnotetext{
Contribution to the Topical Issue "Sunflower / Tournesol".

*Correspondence: nastya.zymaroeva@gmail.com
} 


\section{Introduction}

The world's food security is highly dependent on the rate of increase in yields of key crops (Grassini et al., 2013). The global drivers of crop yields variability include technology, genetics, climate, soil, and field management practices (Kukal and Irmak, 2018; Kucharik and Ramankutty, 2005). The climate and soil conditions are the most important factors in agricultural productivity (Corwin et al., 2003, Xiao et al., 2015, Paixão et al., 2020). It is widely believed that crop yields are highly sensitive to weather conditions. In particular, they depend on long-term trends and climate change (Nelson et al., 2014). Thus, the recent trends in climate change were reported to have a major impact on crop yields, despite advances in cultivation technology (Iizumi and Ramankutty, 2016; Leng and Huang, 2017). Climate change is becoming an increasingly obvious threat to agriculture (Lesk et al., 2016; Ureta et al., 2019) as it causes temperature fluctuations, variations in the precipitation patterns, and more frequent extreme weather events (Schlenker and Roberts, 2009). Droughts and floods are predicted to become more frequent and intense in the near future (Lobell et al., 2011; Fishman, 2016). There are many aspects of the global warming impact on agriculture. In particular, a minimal rise in temperature can increase yields in the temperate climates, while an extreme rise can lead to a decrease in yields (Lobell et al., 2011). There is strong evidence that the frequency of extreme temperatures will increase in many regions of the world (Schlenker and Roberts, 2009). Therefore, it is important to understand how yields are affected by the changes in various climatic variables in order to develop more accurate yield predictions and appropriate adaptation and mitigation strategies (Lobell et al., 2011; Ureta et al., 2019).

The relationship between crop and soil is complex and depends on a variety of interactions between the physical and chemical properties of the soil and other external environmental factors (Sys et al., 1991). A soil-plant interaction is considered to be the most significant factor contributing to the spatial variability of the crop yield (Corwin et al., 2003). Despite the fact that many research publications have highlighted the influence of different soil properties on yield, a quantitative assessment of their contribution to the spatial variability of sunflower yield parameters has not yet been performed (Andrews and Carrol, 2001, Corwin et al., 2003; Cox et al., 2003, Rodrigues et al., 2012; Fedoniuk et al., 2020).

Sunflower (Helianthus annuus L.) is one of the top three oilseeds in the world (along with soybeans and rapeseed) and is one of the two most productive oilseeds in the European Union (along with rapeseed). According to a USDA report, Ukraine is now the world's number one producer of sunflowers, with a $29.3 \%$ share ( 40.57 million tons) of the world's total production of sunflowers (USDA, 2017). However, the environmental factors limit the average sunflower yield to between $1.5-3.0 \mathrm{t} / \mathrm{ha}$. Although, according to a number of recent studies, the introduction of new high-yielding varieties and improvement of sunflower cultivation technologies for specific climatic zones will provide 2.9-3.5 t/ha of sunflower seeds (Melnyk et al., 2018). It should be noted that further growth of global sunflower seed production is expected mainly from Ukraine without expansion of the cropland base. Therefore, understanding the relationship between edaphic and climatic factors, on the one hand, and sunflower yields, on the other, might provide insights into yield forecasting and adaptation of this crop to predictable climatic changes.

In this study, we will focus on the three interrelated research questions: (1) what were the sunflower yield trends in Ukraine from 1991 to 2017; (2) whether the trend model parameters can be used to meaningfully interpret the causes of yield dynamics; and (3) what soil and climatic indicators are capable of predicting the spatial variation in sunflower yield parameters. The purpose of this study is to determine the contribution of edaphoclimatic factors to the spatial and temporal variation of sunflower yield parameters in the Central European mixed forests (Polissya) and Eastern European forest-steppe ecoregions in Ukraine.

\section{Materials and methods}

\subsection{Yield data and study area}

Sunflower yield data were retrieved from the State Statistics Service of Ukraine (http://www.ukrstat.gov.ua/). The time series data sets contain the average annual sunflower yields in 206 administrative districts of 10 regions of Ukraine (Cherkasy, Chernihiv, Khmel'nyts'kyy, Kiev, L'viv, Rivne, Ternopil', Vinnytsya, Volyn, Zhytomyr) for the period 19912017 (Fig. 1). The data represent the average yield values based on the spatial criterion without differentiation of soil water availability and fertility, irrigation management, cultivation and crop rotation. The study area is located in two natural vegetation and climate zones: the Forest zone (Polissya) and the Forest-steppe zone.

\subsection{Selection of the yield dynamics model}

Polynomials of different orders (Ray et al., 2012) and a log-logistic model were considered to select the analytical form of the trend. The yield trends were analyzed using increasing order regression models for: an intercept-only model (constant) (Eq. (1)), a linear model (Eq. (2)), a quadratic model (Eq. (3)), a cubic model (Eq. (4)) and a quartic model (Eq. (5)):

$$
\begin{gathered}
\mathrm{Y}_{x}=b \\
\mathrm{Y}_{x}=b+a_{1} x, \\
\mathrm{Y}_{x}=b+a_{1} x+a_{2} x^{2}, \\
\mathrm{Y}_{x}=b+a_{1} x+a_{2} x^{2}+a_{3} x^{3}, \\
\mathrm{Y}_{x}=b+a_{1} x+a_{2} x^{2}+a_{3} x^{3}+a_{4} x^{4},
\end{gathered}
$$

where: $\mathrm{Y}_{x}$ : crop yield at a certain period of time $x ; b, a_{1}, a_{2}, a_{3}$, $a_{4}$ : coefficients.

We hypothesized that the sunflower yield trend can best be depicted by a sigmoid curve, namely a symmetric four- 

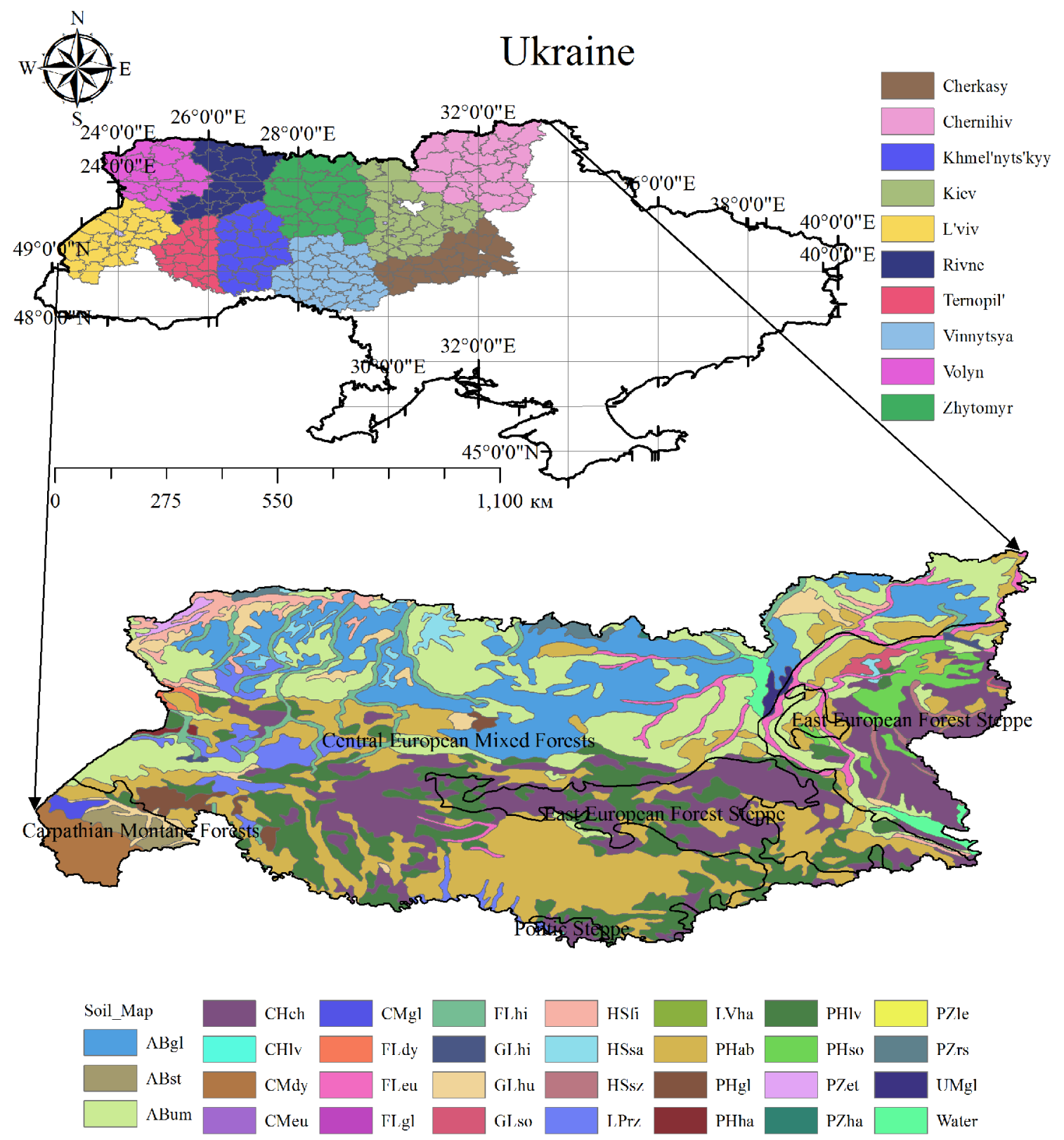

Fig. 1. Map of 10 administrative region in Ukraine, Ecoregions and soil map. Soil classification according World Reference Base for Soil Resources: ABgl-Albeluvisols Gleyic; ABst-Albeluvisols Stagnic; ABum-Albeluvisols Umbric; CHch-Chernozems Chernic; CHlvChernozems Luvic; CMdy-Cambisols Dystric; CMeu-Cambisols Eutric; CMgl-Cambisols Gleyic; FLdy-Fluvisols Dystric; FLeuFluvisols Eutric; FLgl-Gleyic Fluvisols; FLhi-Fluvisols Histic; GLhi-Gleysols Histic; GLhu-Gleysols Humic; GLso-Gleysols Sodic; HSfi-Histosols Fibric; HSsa - Histosols Sapric; HSsz-Histosols Salic; LPrz-Leptosols Rendzic; LVha - Haplic Luvisols; PHab-Phaeozems Albic; PHgl-Phaeozems Gleyic; PHha-Phaeozems Haplic; PHlv-Phaeozems Luvic; PHso-Phaeozems Sodic; PZet-Podzols Entic; PZha-Podzols Haplic; PZle-Leptic Podzols; PZrs - Podzols Rustic.

parameter log-logistic model (Eq. (6)):

$$
\mathrm{Y}=c+\frac{d-c}{1+\exp (b(\log (x)+\log (E D 50)))},
$$

where $x$ represents years $(1-1991,2-1992, \ldots) ; y$ is the response (crop yield); $c$ shows the lower response limit (the lowest yield level); $d$ is the upper limit (the plateau level of yields) when $x$ approaches infinity; $b$ is a slope of the response curve near the inflection point when $x$ acquires ED50 (the time it takes to reach half increase between the lower and upper limits). Lower Limit indicates the lowest level of yield over the study period; Slope - the slope of the trend curve, which shows the rate of change in yield over time; ED50-the time required to reach half of the maximum yield level, and the point with the highest rate of yield growth; Upper Limit - the highest level of yield, which at the present state of agricultural technology is determined by the biotic potential of the territory. The sigmoid 
Table 1. Bioclimatic variables (according to https://worldclim.org/ data/worldclim21.html).

\begin{tabular}{ll}
\hline Variable & Specification \\
\hline bio_1 & Annual Mean Temperature \\
bio_2 & $\begin{array}{l}\text { Mean Diurnal Range (Mean of monthly } \\
\left(\text { temp }_{\max }-\text { temp } \text { min }_{\text {mo }}\right)\end{array}$ \\
bio_3 & Isothermality (bio_2/bio_7) $(\times 100)$ \\
bio_4 & Temperature Seasonality (standard deviation $\times 100)$ \\
bio_5 & Max Temperature of Warmest Month \\
bio_6 & Min Temperature of Coldest Month \\
bio_7 & Temperature Annual Range (bio_5-bio_6) \\
bio_8 & Mean Temperature of Wettest Quarter \\
bio_9 & Mean Temperature of Driest Quarter \\
bio_10 & Mean Temperature of Warmest Quarter \\
bio_11 & Mean Temperature of Coldest Quarter \\
bio_12 & Annual Precipitation \\
bio_13 & Precipitation of Wettest Month \\
bio_14 & Precipitation of Driest Month \\
bio_15 & Precipitation Seasonality (Coefficient of Variation) \\
bio_16 & Precipitation of Wettest Quarter \\
bio_17 & Precipitation of Driest Quarter \\
bio_18 & Precipitation of Warmest Quarter \\
bio_19 & Precipitation of Coldest Quarter \\
\hline
\end{tabular}

model is used to predict both the time effect of and the dose effect on the response being studied. Therefore, the parameter describing the inflection point of the sigmoid curve is traditionally designated as "ED50" (Ritz et al., 2015).

The Akaike Information Criterion (AIC) developed by Akaike (1974) was used to estimate the compatibility of the statistical models (Eqs. (1)-(6)) with the observed data. AIC was computed for each of the six models (Eq. (7)):

The Akaike Information Criterion (AIC) developed by Akaike (1974) was used to estimate the compatibility of the statistical models (Eqs. (1)-(6)) with the observed data. AIC was computed for each of the six models (Eq. (7)):

$$
A I C=n \log \left(\frac{s S}{n}\right)+2 p,
$$

here, $s s$ is the residual sum of squares, $n$ is the sample size, and $p$ is the number of parameters.

The best model to describe the yield dynamics per administrative district was the one with the lowest AIC. All calculations and data analyses were performed using $\mathrm{R}$ v 3.0.2 (R Development Core Team, 2018).

\subsection{Edaphoclimatic characteristics}

Bioclimatic data were retrieved from the WorldClim database version 2 (http://worldclim.org/version2) (Fick and Hijmans, 2017). The climatic information is presented in the form of raster maps with a resolution of $1 \mathrm{~km}$, which is sufficient for the purposes of the study. The bioclimatic variables represent ecologically significant aspects of annual temperature and precipitation changes (Tab. 1).

Data on spatial variability of soil properties and information on soil classification were retrieved from the SoilGrids

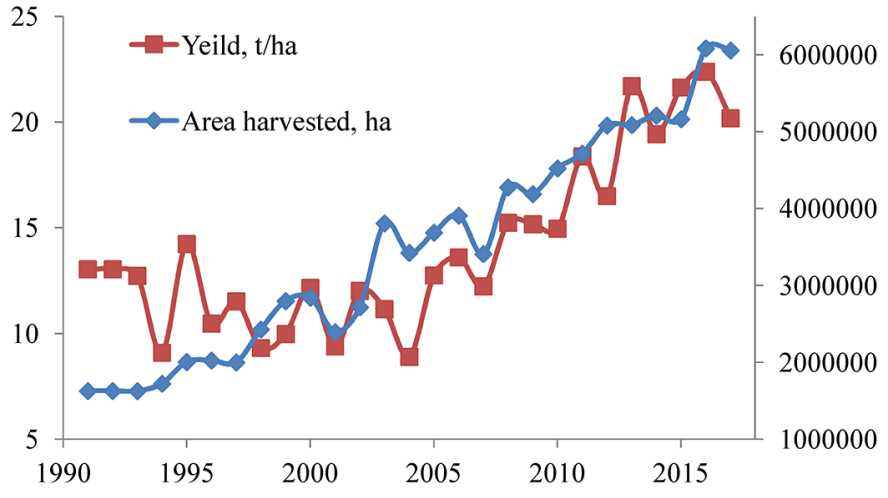

Fig. 2. Dynamics of sunflower yields and area harvested in Ukraine in 1991-2017 (source-FAOSTAT, http://www.fao.org).

database (https://soilgrids.org) (Hengl et al., 2017). The following indicators were used to analyze the influence of soil factors on yield: soil organic carbon (SOC), $\mathrm{pH}$, soil bulk density, sand, clay or silt content in different soil layers.

\section{Data analysis}

The Box-Cox transformation was applied to transform non-normal dependent variables into a normal form, which was done using the AID library (Osman et al., 2014) for a Language and Environment for Statistical Computing R (R Core Team, 2018). Principal component analysis was used for dimensionality reduction of climate and soil matrices. General linear models were employed to test the significance of the climate and soil influence on the yield parameters. Statistical analysis was performed using Statistica 10 software.

\section{Results}

\subsection{Analysis of the spatial variation of yield trend parameters}

Within Ukraine, the growth of sunflower cultivated areas during the study period was gradual, while the yield of this crop had a more complex dynamic (Fig. 2). The sunflower yield in the study region varied within a fairly narrow range until 2010, when there was a sharp increase with a peak in 2016 (Fig. 3). Along with the increase in yields, there was an expansion of cultivation areas, as sunflower became a strategically important crop for Ukraine (Zhygailo and Zhygailo, 2016; Melnyk et al., 2018). The dynamics of sunflower yields in most administrative regions were best explained by the log-logistic model (Fig. 4). The parameters of the logistic model showed regular spatial patterns (Fig. 5), which were obviously caused in most cases by the spatial variability of edaphoclimatic factors. It is noteworthy that despite the higher average sunflower yields in the Foreststeppe ecoregion, Polissya exceeded it in the rate of yield growth (slope) (Fig. 5A). In accordance with the dependencies established in this work, both the minimum and the maximum sunflower yield levels were higher in the southern part of the study region (Forest-steppe) (Figs. 5C and 5D). Those areas, 


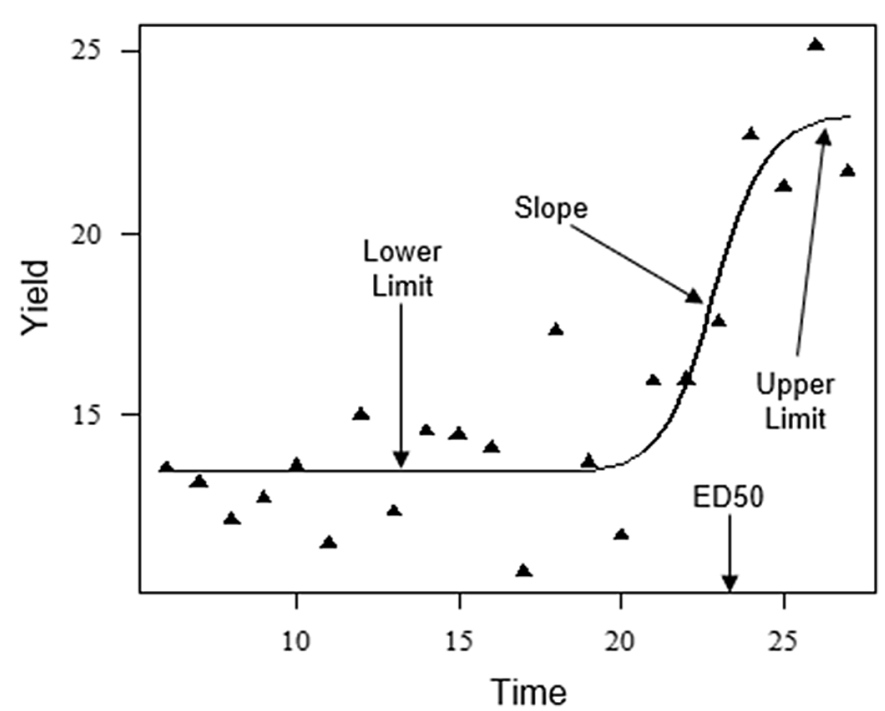

Fig. 3. Typical dynamics of the sunflower yield between 1991 and 2017 and its approximation by logistic model. The abscissa axis-years, the ordinate axis is the sunflower yield, $\mathrm{dt} \cdot \mathrm{ha}^{-1}$.

where the Upper Limit of sunflower yields was high (Fig. 5B), required longer periods of time to reach half of the maximum yield level (ED50), which is quite self-evident.

\subsection{Principal component analysis of climatic variables}

Principal component analysis allowed to identify four principal components, whose eigenvalues were greater than 1 and which together account for $92.5 \%$ of the total variance of climatic variables (Tab. 2). Principal component 1 (PC1) explains $54.45 \%$ of the total variance. PC1 was most strongly correlated with bioclimatic variable 8 (average temperature of the wettest quarter), bioclimatic variable 4 (temperature seasonality), bioclimatic variable 5 (maximum temperature of the warmest month), bioclimatic variable 10 (average temperature of the warmest quarter), bioclimatic variable 17 (precipitation of the driest quarter) and bioclimatic variable 18 (precipitation of the warmest quarter). The set of these variables indicates that $\mathrm{PC} 1$ can be interpreted as a characteristic feature of climatic continentality. The spatial variation of the values of $\mathrm{PC} 1$ in the latitudinal direction confirms our assumption (Fig. 6). Principal component 2 (PC2) accounts for $23.78 \%$ of the total variance. This component was most strongly correlated with bioclimatic variable 9 (mean temperature of the driest quarter), and 11 (mean temperature of the coldest quarter), which allowed $\mathrm{PC} 2$ to be interpreted as an indicator of temperature variability during extreme periods of the year. The northeastern and northern zones of the study area were clearly distinguished by the criterion of temperature extremity. Principal component 3 (PC3) accounts for $8.18 \%$ of the total variance. This component was most strongly influenced by bioclimatic variables 2 (mean diurnal range) and 3 (isothermality). These features reveal that PC3 indicates the degree of annual temperature variability. Principal component 4 (PC4) explains $6.03 \%$ of the total variance. PC4 was mostly determined by bioclimatic variable 2 (mean diurnal range), 6 ( $\mathrm{min}$ temperature of the coldest month), and

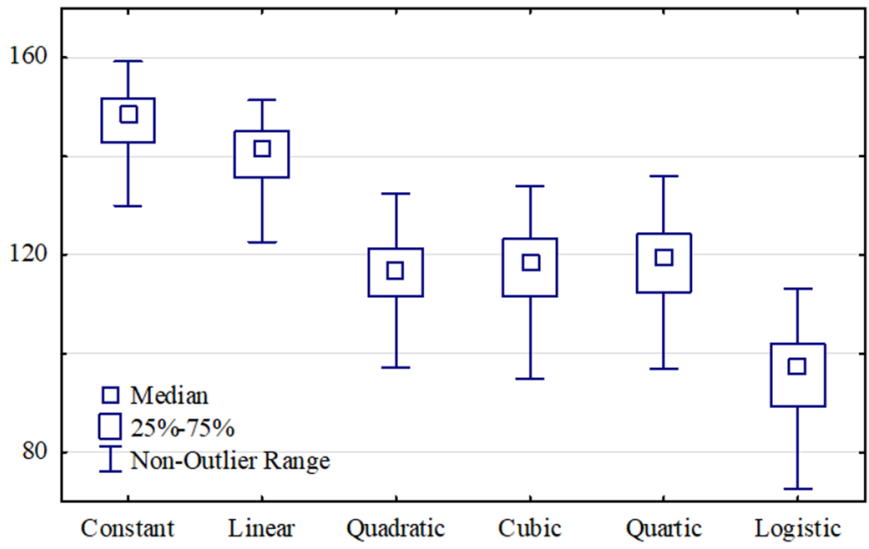

Fig. 4. The Akaike criterion for different models of the sunflower yield trend in administrative regions $(\mathrm{N}=206)$.

7 (temperature annual range). This component indicates annual temperature contrast.

\subsection{Principal component analysis of soil properties}

Principal component analysis (PCA) was performed to identify the soil indicators that have the greatest influence on the sunflower yield. The analysis revealed 6 principal components, which together explain $98.5 \%$ of the total variance of soil properties (Tab. 3). Principal component 1 (PC1) explains $65.63 \%$ of the total variance. PC1 correlated with most of the soil variables, but the highest correlation was observed with the sand, clay, and silt content. Consequently, $\mathrm{PC} 1$ is an indicator of granulometric composition and is most sensitive to the sand content. The spatial variation of this principal component is shown in Figure 7. The territories with the predominance of the sand fraction in the soil are located in the north of the studied region (Polissya). Principal component 2 accounts for $14.5 \%$ of the total variance. This component most closely correlates with the soil bulk density. The mapping of principal component 3 indicates a complexity of the spatial configuration of soils with different soil bulk densities (Fig. 6). PC3 explains $6.4 \%$ of the total variance of soil variables. PC 3 was most strongly affected by SOC. Principal component 4 accounts for $5.69 \%$ of the total variance. PC4 was significantly correlated with the silt content in the soil. Soils with the highest silt content are located in the south and southwest of the study area, where there is also a very high content of SOC. Principal component 5 accounts for $3.88 \%$ of the total variance of soil variables, showing the strongest correlation with soil acidity $(\mathrm{pH})$ and having higher values in the northeast of the study region. Principal component 6 accounts for $2.41 \%$ of the total variance and is most sensitive to the silt and clay fractions. The territories with higher PC6 indices are located in the south of the region.

\subsection{Variation in parameters of yield models explained by edaphoclimatic factors}

The results of the regression analysis showed that the climatic and edaphic principal components can explain from 34 to $58 \%$ of the variation in sunflower yield parameters 

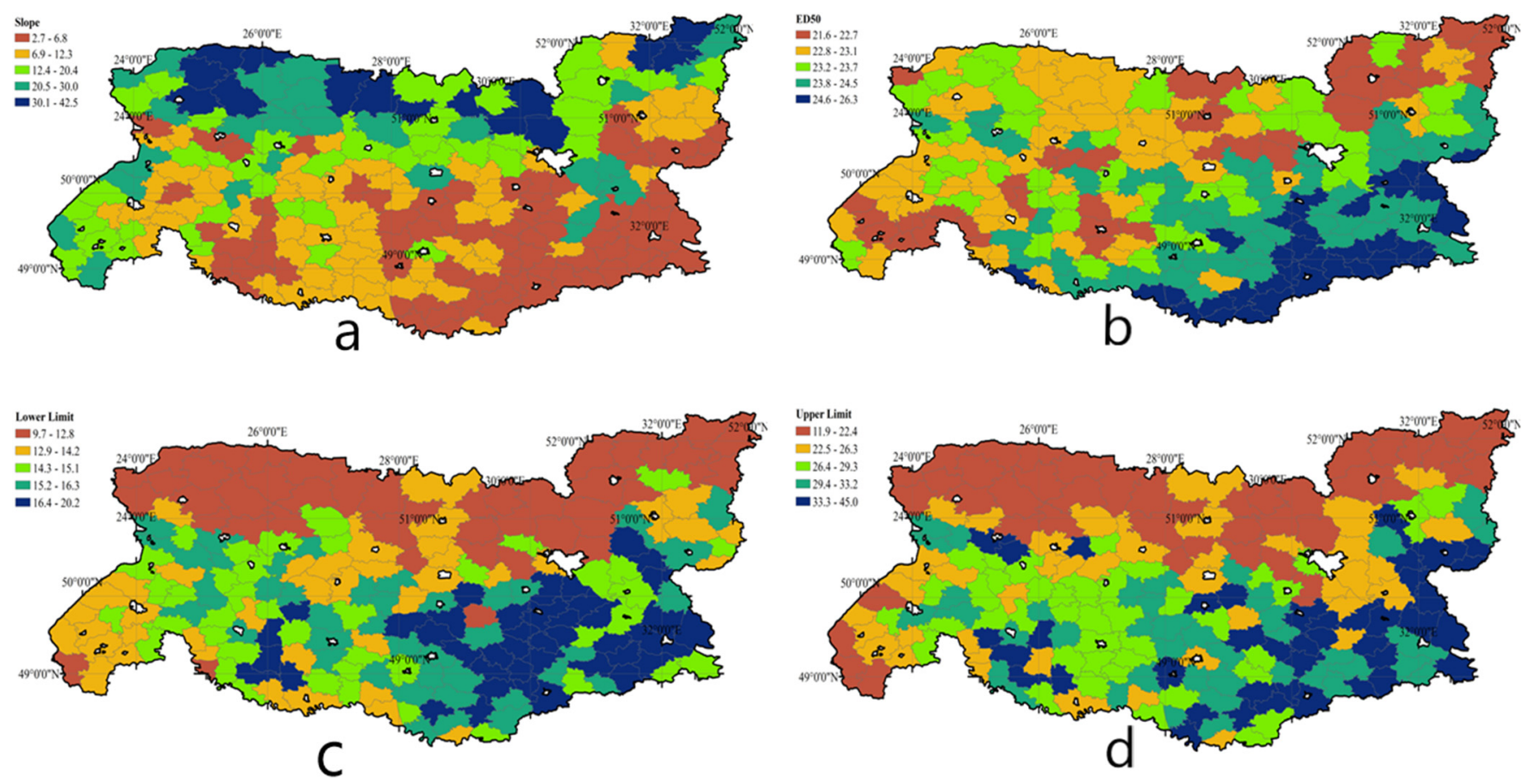

Fig. 5. Spatial variation of parameters of the sunflower yield dynamics log-logistic model: a: Slope; b: ED50; c: lower limit; d: upper limit.

Table 2. The principal component analysis of bioclimatic variables.

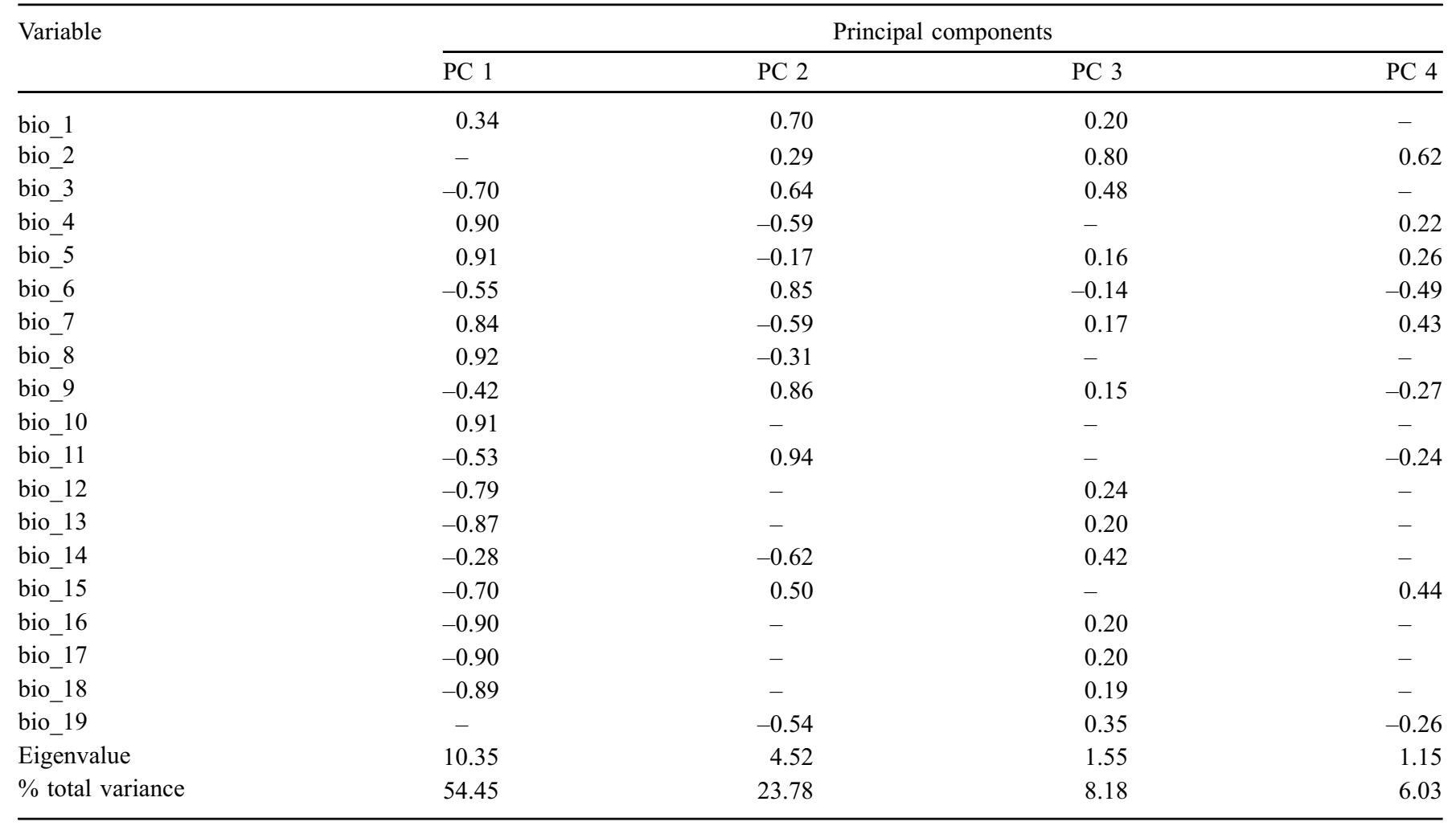

The correlation coefficients statistically significant at $p<0.05$ presented only. 

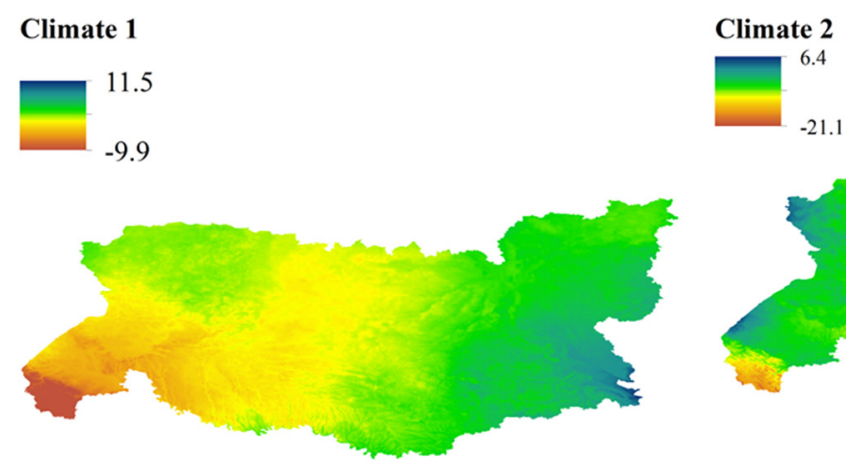
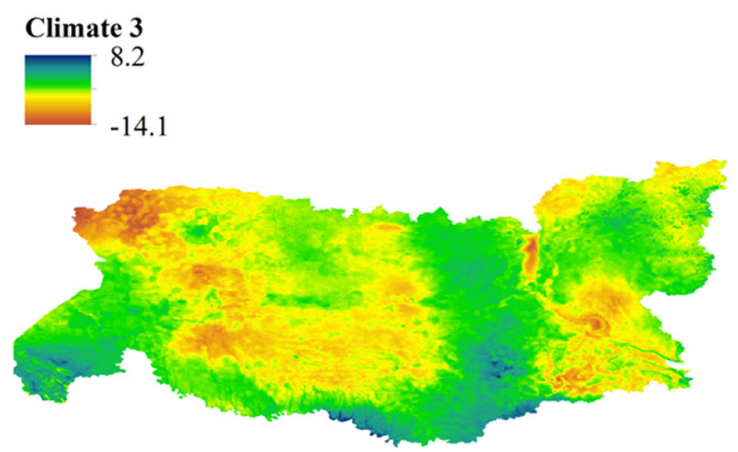

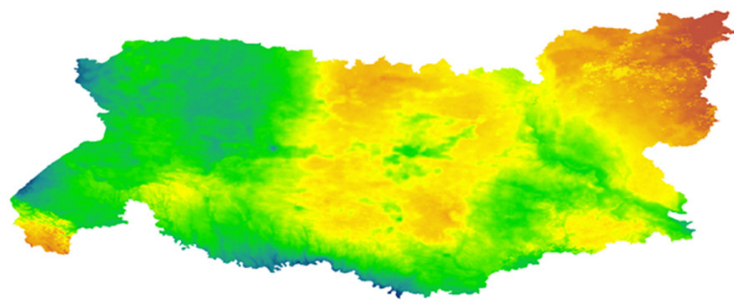

\begin{tabular}{|r} 
Climate 4 \\
5.2 \\
\\
-5.9
\end{tabular}

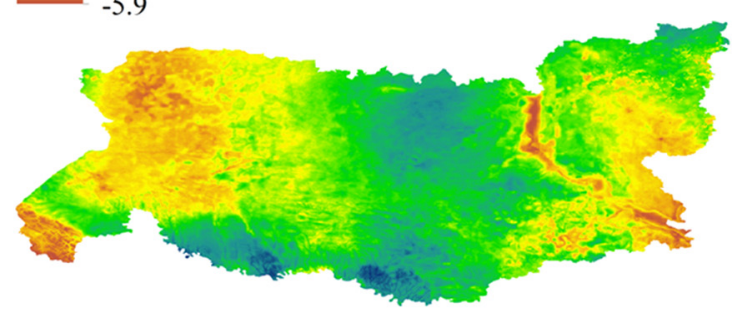

Fig. 6. Spatial variation of bioclimatic principal components.

(Tab. 4). Soil principal components 1 and 2 were the most important factors that determine the growth rate of sunflower yield (slope of the curve) (Tab. 4). Granulometric composition, which was explained by PC1, was the most important soil property determining a dynamic yield behavior. The relationship between the Slope parameter of the sunflower yield trend and edaphic PC1 may be described by the regression coefficient which was found to be equal $\mathrm{R}=0.67 \pm 0.09$, $P<0.01$. The climatic factors of temperature variability (climate principal components 2 and 3) have a much less impact on this parameter of the sunflower yield trend than the soil factors. The Lower Limit of sunflower yield was the most sensitive parameter of the sunflower yield trend to the effects of edaphic and climatic factors ( $\operatorname{Radj} 2=0.58, \mathrm{~F}=28.9$, $P<0.001$ ) (Tab. 4). This sunflower yield trend parameter was influenced by both climatic and edaphic factors. Among the climatic factors, PC1-climatic was the most important component (regression coefficient was $0.41 \pm 0.09, P<0.01$ ), as well as with the edaphic factors PC1-edaphic was also the most significant one (regression coefficient was $-0.59 \pm 0.09$, $P<0.01)$. A complex combination of climatic factors influenced the maximum sunflower yield parameter (Upper Limit) (Tab. 4). The abovementioned principal components are orthogonal variables, and thus statistically independent. Nevertheless, they all determined the Upper Limit of this crop yield. The predominant factors proved to be climatic continentality and degree of temperature variability. Among the soil properties, SOC was the most important factor that determined the upper limit of sunflower yield. The ED50 parameter showed sensitivity to almost the same factors as did the upper yield limit. ED50 was largely determined by climatic
PCs 1 and 3. The most important climatic factor for changes in this parameter, as well as for other sunflower yield parameters, was climatic continentality. In addition, the ED50 parameter was influenced by the SOC and the soil bulk density.

\section{Discussion}

\subsection{The importance of a wide coverage of yield data for predicting the effects of global climate change in agriculture}

The global climate change is causing significant transformations in agricultural practices (Bhadouria et al., 2019). Prediction of such transformations can be based on retrospective studies of crop yields, which assumes a wide geographical coverage of territories (Challinor et al., 2014; Iizumi et al., 2017). This approach assumes that spatial climatic features can be a simulation model of future climate change over time (Schär et al., 1996). Conditions that are observed in some period of time in the south will be observed over time in more and more northern areas (in the southern hemisphere - exactly the opposite). In addition to the trend of modal climatic characteristics (average temperature, total precipitation), which predominantly change in latitudinal direction, the variability of climatic conditions during a year or a growing season will be of particular importance. This variability is very close to such geographical phenomenon as continentality. The continentality in its turn changes gradually in the longitudinal direction. Thus, prediction of trends in agriculture under global climate change requires substantial data on crop yields over a significant temporal and spatial range. 
Table 3. The principal component analysis of soil variables.

\begin{tabular}{|c|c|c|c|c|c|c|c|}
\hline Variable & Layer, $\mathrm{cm}$ & \multicolumn{6}{|c|}{ Principal components } \\
\hline \multirow{4}{*}{$\mathrm{SOC}$} & $0-0.05$ & 0.71 & 0.59 & 0.31 & - & 0.32 & - \\
\hline & $0.15-0.3$ & 0.19 & 0.90 & 0.41 & -0.15 & 0.49 & - \\
\hline & $0.3-0.6$ & 0.24 & 0.84 & 0.52 & -0.26 & 0.48 & 0.16 \\
\hline & 0 & -0.86 & - & - & -0.32 & 0.23 & - \\
\hline \multirow{4}{*}{$\mathrm{pH}$} & $0-0.05$ & -0.91 & - & 0.17 & -0.14 & 0.18 & - \\
\hline & $0.05-0.15$ & -0.91 & - & 0.18 & -0.14 & 0.19 & - \\
\hline & $0.15-0.3$ & -0.89 & - & 0.15 & -0.15 & 0.19 & - \\
\hline & $0.3-0.6$ & -0.88 & - & 0.25 & -0.22 & 0.19 & - \\
\hline \multirow{7}{*}{ Bulk density } & $0-0.05$ & -0.57 & -0.63 & 0.26 & - & - & - \\
\hline & $0.05-0.15$ & -0.27 & -0.75 & 0.34 & - & - & - \\
\hline & $0.15-0.3$ & - & -0.78 & 0.28 & 0.31 & - & - \\
\hline & $0.3-0.6$ & 0.41 & -0.63 & - & 0.39 & - & 0.22 \\
\hline & $0.6-1$ & 0.81 & -0.29 & 0.29 & 0.16 & - & 0.22 \\
\hline & $1-2$ & 0.81 & -0.31 & 0.30 & - & - & 0.20 \\
\hline & 0 & 0.98 & - & 0.34 & -0.19 & -0.14 & - \\
\hline \multirow{4}{*}{ Sand } & $0-0.05$ & 0.98 & - & 0.35 & -0.19 & -0.14 & - \\
\hline & $0.05-0.15$ & 0.98 & - & 0.34 & -0.19 & -0.14 & - \\
\hline & $0.15-0.3$ & 0.98 & - & 0.33 & -0.18 & -0.14 & - \\
\hline & $0.3-0.6$ & 0.98 & - & 0.32 & -0.17 & -0.15 & - \\
\hline \multirow{9}{*}{ Silt } & $0.6-1$ & -0.95 & - & -0.20 & 0.28 & - & 0.18 \\
\hline & $1-2$ & -0.95 & - & -0.23 & 0.30 & - & 0.18 \\
\hline & 0 & -0.94 & - & -0.34 & 0.37 & 0.18 & -0.22 \\
\hline & 0-0.05 & -0.94 & - & -0.34 & 0.37 & 0.18 & -0.22 \\
\hline & $0.05-0.15$ & -0.94 & - & -0.34 & 0.37 & 0.18 & -0.23 \\
\hline & $0.15-0.3$ & -0.94 & - & -0.34 & 0.35 & 0.18 & -0.23 \\
\hline & $0.3-0.6$ & -0.95 & - & -0.30 & 0.31 & 0.20 & -0.24 \\
\hline & $0.6-1$ & -0.95 & - & -0.29 & 0.29 & 0.20 & -0.24 \\
\hline & $1-2$ & -0.96 & - & -0.28 & 0.29 & 0.20 & -0.23 \\
\hline \multicolumn{2}{|c|}{ Eigenvalue } & 28.49 & 6.29 & 2.78 & 2.47 & 1.69 & 1.05 \\
\hline \multicolumn{2}{|c|}{$\%$ Total variance } & 65.63 & 14.50 & 6.40 & 5.69 & 3.88 & 2.41 \\
\hline
\end{tabular}

The correlation coefficients statistically significant at $p<0.05$ presented only.

\subsection{Non-stationarity of agricultural production in Ukraine for the last 30 years}

A possibility of prediction is based on the stationarity of the process to be predicted (Gyöfi and Lugosi, 2002; Ryabko and Hutter, 2008). Abrupt changes in the dynamics of the process indicate its qualitative transformation, which makes it difficult or impossible to use retrospective data. Crop yield dynamics studies tend to refer to countries that have been developing systematically without catastrophic socio-economic crises. Recently, the long-term trends in crop yields on a global scale have been extensively studied around the world 

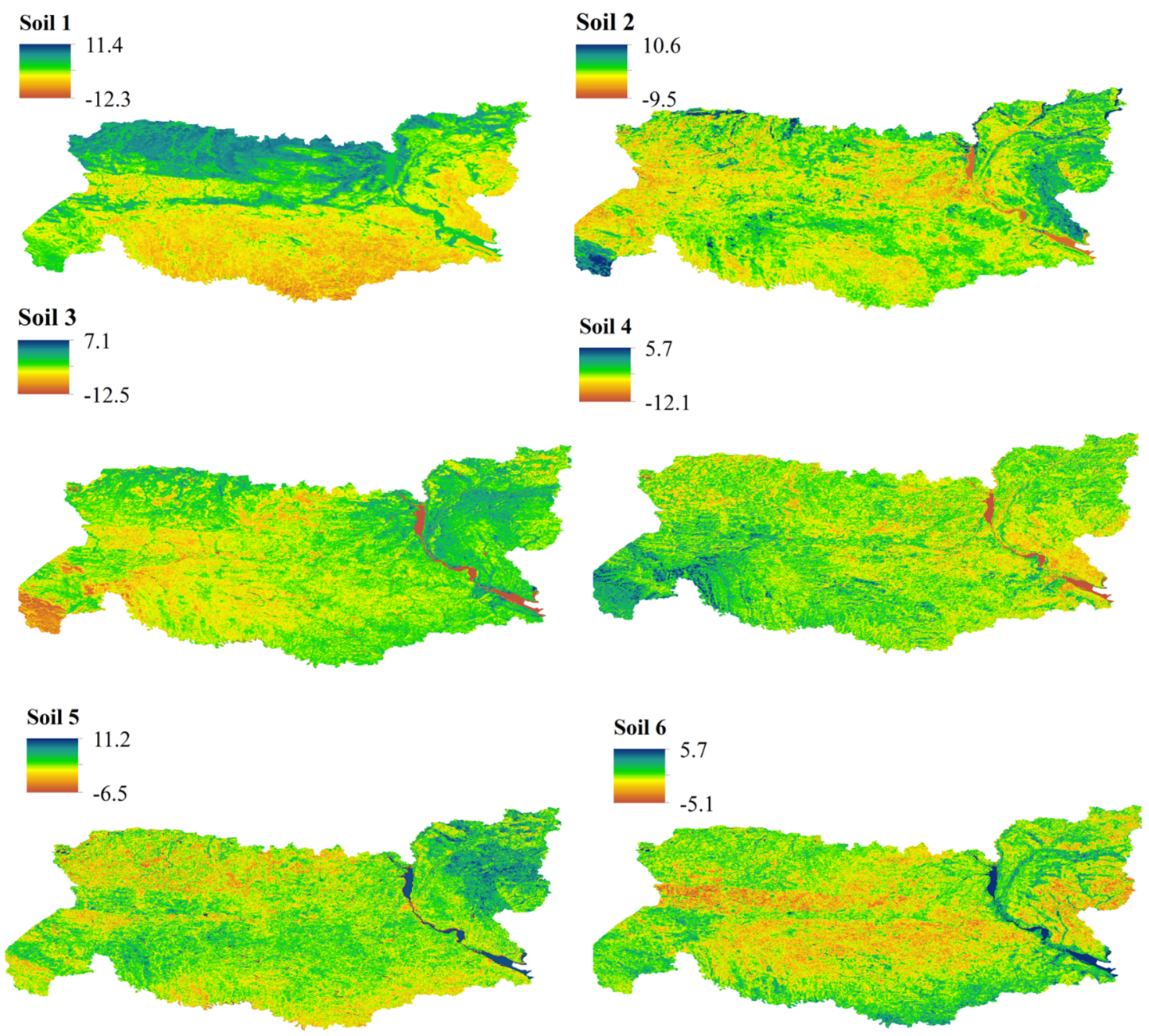

Fig. 7. Spatial variability of soil principal components 1-6.

Table 4. Regression dependence of the sunflower yield parameters on the climate and soil variables*

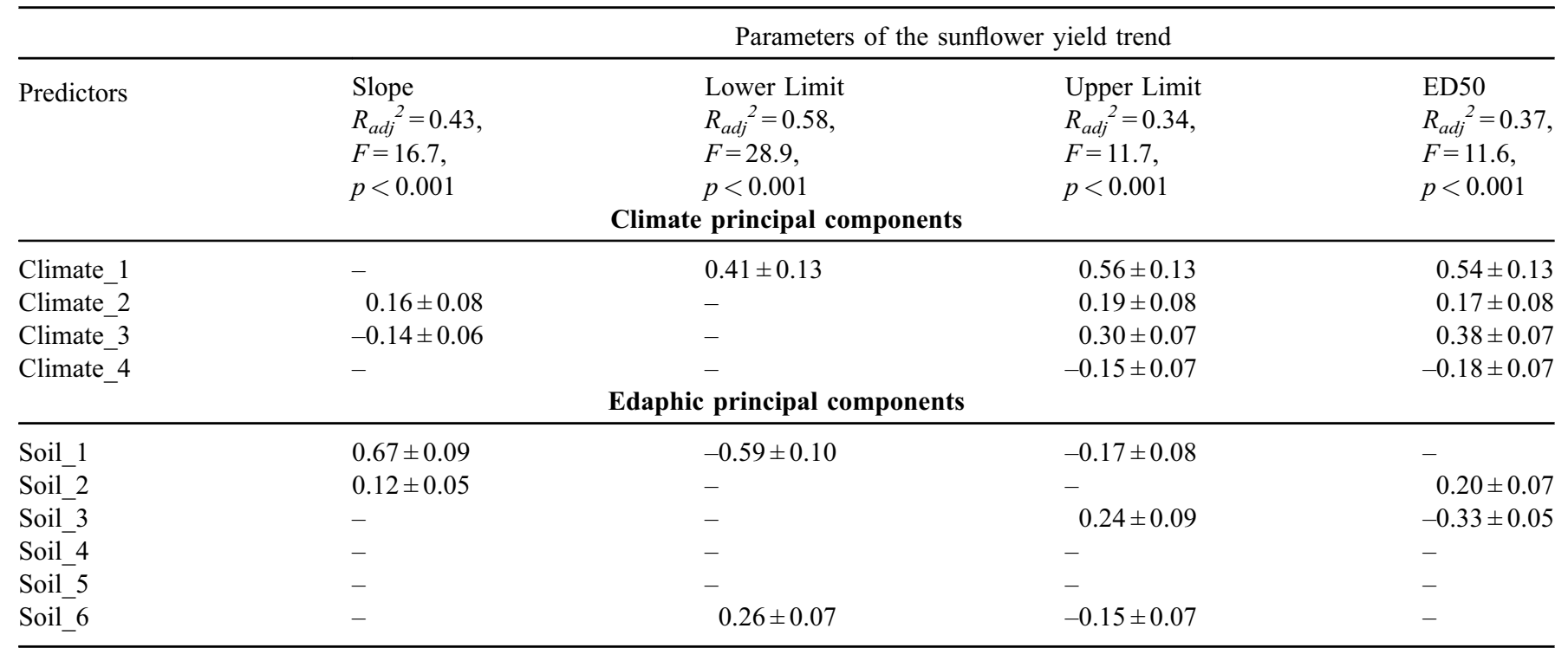

*Note: Standardized regression coefficients, statistically significant at $P<0.01$. 
(Godfray et al., 2010; Ray et al., 2012; Lesk et al., 2016). In particular, Chen (2018) demonstrated the application of a mathematical method in the analysis of spatial patterns in the long-term temporal yield trends of three major crops (rice, wheat, and soybeans) in Japan. Yield trends in the prefectures of Japan were divided into four types: Intercept-only model, Linear model, Quadratic model and Cubic model (Chen, 2018). In our previous study, it was found that the general trends in the yield of major crops in Ukraine for the period 1990-2017 best fitted the fourth order polynomial (Quartic model) (Kunah et al., 2018, Zymaroieva et al., 2019, Zymaroieva et al., 2020a). During the study period, the sunflower yield tended to increase, except for the initial stage of research (1991-1997), when there was a rapid decrease in the crop (Zymaroieva et al., 2019b). However, the used polynomials of increasing order cannot satisfactorily describe the observed dynamics of crop yields in Ukraine after the collapse of the USSR (Zhukov et al., 2018). In addition, the parameters of such models, with the exception of the linear model, cannot be meaningfully interpreted, so there is no reason to use polynomial models to explain them with climatic or edaphic factors. Considering the dynamics of yield from the mid90s to the current time, it can be depicted by a sigmoid curve, namely a log-logistic curve. Thus, in this study we showed that a symmetric log-logistic model most adequately reflects the dynamics of sunflower yield. This type of curve includes certain characteristic stages which meaningfully reflect the properties of the observed sunflower yield dynamics, namely: a) stagnation at the initial stage with a significant yield variability; b) a sharp growth in the middle part of the study period; c) stabilization of the growth in the last third of the study period, and in some cases reaching a plateau. These stages differ in their genesis, in which the ratio of economic and environmental factors changes over time. Of course, the initial stage was the result of the destruction of economic relations in agriculture caused by the collapse of the Soviet Union. Due to formation of market-based relations in agriculture, its efficiency was restored, which manifested itself in the growth of crop yields, including sunflowers. In the last third of the period under study, the maximum yields were achieved under the given level of agricultural technology and environmental conditions. The fourth-order nonlinear model made it possible to describe the above steps with the help of appropriate model parameters to which and we attach a special significance. The model parameters correlate with climatic and edaphic predictors, which allowed us to find that the nature of the influence of environmental factors was different at each stage of the study period. The novelty of our approach is that to describe the dynamics of sunflower yield we applied a model, the parameters of which can be meaningfully interpreted and their spatial and temporal dynamics can be explained by the climatic and edaphic predictors.

\subsection{Soil determinants of sunflower yields}

Soil has a significant degree of resilience, so this component of the landscape is very stable under conditions of global climate change (Kunah et al., 2019; Pakhomov et al., 2019). Of course, climate is the most important factor of soil formation, so the soil will also be affected by global climate change. When predicting changes in sunflower yields, the role of soil conditions is considerable. The importance of soil conditions for a particular crop can vary greatly depending on climatic conditions. Ion et al. (2015) concluded that soil and climatic conditions are among the environmental factors that have the greatest influence on sunflower yield. Among soil properties, soil granulometric structure and SOC are paramount. These findings are in accordance with our study results, indicating that under Ukrainian conditions, sunflower is quite sensitive to edaphic and climatic factors, which can explain from 34 to $58 \%$ of the variations in the parameters of the crop yield dynamics. It should be noted that sunflowers are adaptable to a wide variety of soils and are even successfully cultivated on sandy soils (Hamza and Safina, 2015), nevertheless, the crop gives the best results on good soils suitable for growing corn or wheat (Radanielson et al., 2012). Our study confirmed that sunflower yields positively correlated with the SOC, which directly reflects soil fertility. However, the Upper Limit of sunflower yields was higher in the areas dominated by sandy soils. This may be due to the expansion of sunflower cultivation areas in Polissya, where soils with a high content of the sandy fraction are widespread. The possibility of such expansion is due to a significant warming of the climate, which provides the temperature conditions necessary for this crop in the more northern areas of Polissya. Undoubtedly, improvement of agricultural technology is a prerequisite for increasing the area of sunflower cultivation (Zymaroieva and Zhukov, 2020). It should be noted that a high proportion of the sand fraction should be combined with a high content of organic matter in the soil. Only under these conditions, a significant increase in the Upper Limit of sunflower yield can be expected. Such a combination of soil properties can be found in the floodplain soils of the region. The edaphoclimatic determinants of ED50 (the time that is required to achieve half of the maximum yield level) demonstrate a marked similarity with the Upper Limit determinants, which confirms these parameters close correlation.

\subsection{Climate determinants of sunflower yields}

Continentality reflects the most important climatic properties, such as the degree of variability of the annual temperature range. As continentality increases, summer temperatures rise and winter temperatures fall (Driscoll and Fong, 1992). Our study proved that continentality is the main climatic factor determining the spatial variability of sunflower yield. A higher level of continentality is associated with higher summer temperatures, which positively affects both the Lower and Upper Limits of the sunflower yield trend. This is quite consistent, given the increasing requirements of this crop to the temperature conditions during the reproductive growth period (Esmaeli et al., 2012, Zhygailo and Zhygailo, 2016). All parameters of the yield trend, with the exception of the Slope, showed a dependence on the degree of temperature variability. The annual temperature variability is the result of temperature increase in the summer time period, which is critical for sunflower vegetation. The results obtained can be explained by physiological and environmental reasons. Physiology of yield expression in sunflower indicates that the germination rate of sunflower seeds increases exponentially between 3 and $30^{\circ} \mathrm{C}$, and the maximum percentage of germination is maintained 
between 6 and $23{ }^{\circ} \mathrm{C}$. The germination rate decreases rapidly at temperatures above $25^{\circ} \mathrm{C}$. Sunflower seeds are severely damaged and germination deteriorates at $37-40^{\circ} \mathrm{C}$ (Connor and Sadras, 1992). The favorable temperatures for sunflower growth are in the range of $20-25^{\circ} \mathrm{C}$ (Fernández-Luqueño et al., 2014), so an increasing continentality of the climate contributes to the possibility of achieving optimal temperature conditions for sunflower growth. However, temperatures above $25^{\circ} \mathrm{C}$ and frosts at any stage of growth, which are also signs of the climate's continentality, reduce the yield and oiliness of the seeds (Thomaz et al., 2012). Most of the sunflowers are cultivated under rain-fed conditions in Ukraine. Although sunflowers are capable of adapting to dry conditions (Gürkan et al., 2020), precipitation rate is considered one of the most effective climatic factors in sunflower cultivation under rain-fed conditions (Barros et al., 2004). We found that the precipitation during the driest and warmest quarters also determines sunflower yield. This confirms that sunflower yield is subject to drought stress during the main growing and flowering periods.

Analyses of historical climate data, shows an obvious trend towards increasing temperatures in Ukraine, and climate models predict further warming, especially with regard to winter temperatures. Moreover, the amount of precipitation in the southern steppe zone of Ukraine decreased during 19612009 (Morgounov et al., 2013). According to the forecasts of the Intergovernmental Panel on Climate Change (IPCC, 2013), temperatures in grain-producing regions of Ukraine will rise, with the greatest increases expected in the winter months. Summer precipitation is likely to decrease while winter precipitation is predicted to increase. Droughts may become more probable and long-lasting (Lioubimtseva and Henebry, 2012). Such climatic changes are expected to lead to a decrease in the sunflower yield in the steppe zone of Ukraine, which has already been confirmed for Turkey (Gürkan et al., 2020), but at the same time, yields will increase in the Polissya (northern) region, where the climate is already more continental. Studying the possible effects of climate change on the future of sunflower crop cultivation in Ukraine will be the purpose of our further research.

\subsection{Prospects for further research and practical recommendations}

The global climate changes have a significant impact on the variability of climatic regimes. These circumstances require constant agro-ecological monitoring of crop yields, including sunflowers. Recording the sunflower yield per administrative district in Ukraine provides a significant amount of information, but this spatial level of accuracy of monitoring is not acceptable. Note that the boundaries of administrative districts do not coincide with the boundaries of natural landscape units, which greatly complicates the interpretation of the data obtained. The main argument in favor of yield accounting at the level of administrative districts is the possibility to compare the obtained information with the economic indicators, which correlate with administrative division of the territory. In this regard, assessment of economic factors in view of spatial and temporal variability of sunflower yield is of particular interest.
Long-term climate forecasts may become the basis for assessing the future prospects of sunflower cultivation in the north of Ukraine. The data we obtained also emphasize the importance of soil conditions. Therefore, we consider studies of the impact of climate change on soil cover and consequently on sunflower yields to be a very promising area of research. Sunflower itself is also a crop that substantially affects the soil, so the mutual influence of soil and sunflower in the context of global climate change is a perspective for further research.

The solution of these problems requires an effective system of agro-ecological monitoring, the creation of which can be considered as a practical recommendation. The procedures available in Ukraine for collecting agronomic, climatic and soil data are not linked into a comprehensive information system, whose setting up will provide adequate and balanced management decisions in the context of global climate change.

\section{Conclusions}

The present study reveals a statistically significant dependence between the edaphic and climatic factors and the parameters of the sunflower yield model in the north of Ukraine. It was found that the dynamics of sunflower yield in the studied area can be most adequately described by a loglogistic model. The parameters of the trend model (the Lower Limit, the Slope, the Upper Limit) are spatially dependent and can be used for a meaningful interpretation of the causes of sunflower yield dynamics. The study showed a significant influence of edaphoclimatic factors on sunflower yield parameters. The ratio of granulometric fractions and soil organic carbon (SOC) is the most important soil indicator, which closely correlates with the sunflower yield dynamics. The main climatic drivers of sunflower yields are changes in climate continentality.

\section{Supplementary Material}

The Supplementary Material is available at http://www.ocljournal.org/10.1051/ocl/2021013/olm.

Conflicts of interest. The authors declare that they have no conflicts of interest in relation to this paper.

\section{References}

Akaike H. 1974. A new look at the statistical model identification. IEEE Trans Autom Control 19: 716-723.

Andrews SS, Carrol CR. 2001. Designing a soil quality assessment tool for sustainable agroecosystem management. Ecol Appl 11(6): 1573-1585. https://doi.org/10.2307/3061079.

Barros J, Carvalho M, Basch G. 2004. Response of sunflower (Helianthus annuus L.) to sowing date and plant density under Mediterranean conditions. Eur J Agron 21: 347-356. https://doi. org/10.1016/j.eja.2003.10.005.

Bhadouria R, Singh R, Singh VK, et al. 2019. Agriculture in the Era of Climate Change: Consequences and Effects. In: Climate Change and Agricultural Ecosystems. Elsevier, pp. 1-23. https://doi.org/ 10.1016/B978-0-12-816483-9.00001-3. 
Challinor AJ, Watson J, Lobell DB, Howden SM, Smith DR, Chhetri N. 2014. A meta-analysis of crop yield under climate change and adaptation. Nat Clim Change 4(4): 287-291. https://doi.org/ 10.1038/nclimate2153.

Chen H. 2018. The spatial patterns in long-term temporal trends of three major crops' yields in Japan. Plant Prod Sci 21(3): 177-185. https://doi.org/10.1080/-1343943X2018.1459752.

Connor DJ, Sadras VO. 1992. Physiology of yield expression in sunflower. Field Crops Res 30(3-4): 333-389. https://doi.org/ 10.1016/0378-4290(92)90006-U.

Corwin DL, Lesch SM, Shouse PJ, Soppe R, Ayars JE. 2003. Identifying soil properties that influence cotton yield using soil sampling directed by apparent soil electrical conductivity. Agron $J$ 95(2): 352-364. https://doi.org/10.2134/agronj2003.0352.

Cox MS, Gerard DP, Wardlaw MC, Abshire MJ. 2003. Variability of selected soil properties and their relationships with soybean yield. Soil Sci Soc Am J 67: 1296-1302. https://doi.org/10.2136/ sssaj2003.1296.

Driscoll DM, Fong JMY. 1992. Continentality: A basic climatic parameter re-examined. Int J Climatol 12(2): 185-192. https:// doi.org/10.1002/joc.3370120207.

Esmaeli M, Javanmard HR, Nassiry BM, Soleymani A. 2012. Effect of different plant densities and planting pattern on sunflower (Helianthus annuus L.) cultivars grown under climatic conditions of Isfahan region of Iran. Res Crops 13(2): 517-520.

Fedoniuk RH, Fedoniuk TP, Zimaroieva AA, Pazych VM, Zubova OV. 2020. Impact of air born technogenic pollution on agricultural soils depending on prevailing winds in Polissya region (NW Ukraine). Ecol Quest 31(1): 1-24. http://dx.doi.org/10.12775/ EQ2020.007.

Fernández-Luqueño F, López-Valdez F, Miranda-Arámbula M, Rosas-Morales M, Pariona N, Espinoza-Zapata R. 2014. An Introduction to the Sunflower Crop. In: Arribas JI, ed. Sunflowers: Growth and Development, Environmental Influences and Pests/ Diseases. Valladolid, Spain: Nova Science Publishers, pp. 1-18.

Fick SE, Hijmans RJ. 2017. Worldclim 2: New 1-km spatial resolution climate surfaces for global land areas. Int J Climatol 37: 4302-4315. https://doi.org/10.1002/joc.5086.

Fishman R. 2016. More uneven distributions overturn benefits of higher precipitation for crop yields. Environ Res Lett 11(2): 024004. https://doi.org/10.1088/1748-9326/11/2/024004.

Godfray HCJ, Beddington JR, Crute IR, et al. 2010. Food security: the challenge of feeding 9 billion people. Science 327(5967): 812 818. https://doi.org/10.1126/science.1185383.

Grassini P, Eskridge KM, Cassman KG. 2013. Distinguishing between yield advances and yield plateaus in historical crop production trends. Nat Commun 4: 2918. https://doi.org/10.1038/ ncomms3918.

Gürkan H, Ozgen Y, Bayraktar N, Bulut H, Yildiz M. 2020. Possible Impacts of Climate Change on Sunflower Yield in Turkey. Available at: https://www.intechopen.com/online-first/possibleimpacts-of-climate-change-on-sunflower-yield-in-turkey (Accessed 22 April 2020).

Gyöfi L, Lugosi G. 2002. Strategies for Sequential Prediction of Stationary Time Series, pp. 225-248. https://doi.org/10.1007/ 0-306-48102-2_11.

Hamza M, Safina S. 2015. Performance of sunflower cultivated in sandy soils at a wide range of planting dates in Egypt. J Plant Prod 6: 821-835. https://doi.org/10.21608/jpp.2015.49782.

Hengl T, Mendes de Jesus J, Heuvelink GBM, et al. 2017. SoilGrids250m: Global gridded soil information based on machine learning. PLoS ONE 12(2): e0169748. https://doi.org/ 10.1371/journal.pone.0169748.
Iizumi T, Ramankutty N. 2016. Changes in yield variability of major crops for 1981-2010 explained by climate change. Environ Res Lett 11(3): 034003. https://doi.org/10.1088/1748-9326/11/3/ 034003.

Iizumi T, Furuya J, Shen Z, et al. 2017. Responses of crop yield growth to global temperature and socioeconomic changes. $S c i$ Rep 7(1): 7800. https://doi.org/10.1038/s41598-017-08214-4.

Ion V, Dicu G, Basa A, et al. 2015. Sunflower Yield and Yield Components under Different Sowing Conditions. Agric Agric Sci Proc 6. https://doi.org/10.1016/j.aaspro.2015.08.036.

IPCC. 2013. Climate Change 2013: The Physical Science Basis. Contribution of Working Group I to the Fifth Assessment Report of the Intergovernmental Panel on Climate Change. Cambridge, United Kingdom and New York, NY, USA: Cambridge University Press.

Kucharik CJ, Ramankutty N. 2005. Trends and variability in US corn yields over the twentieth century. Earth Interact 9: 1-29. https:// doi.org/10.1175/EI098.1.

Kukal MS, Irmak S. 2018. Climate-Driven Crop Yield and Yield Variability and Climate Change Impacts on the U.S. Great Plains. Agricultural Production. Sci Rep 8: 3450. https://doi.org/10.1038/ s41598-018-21848-2.

Kunah OM, Pakhomov OY, Zymaroieva AA, et al. 2018. Agroeconomic and agroecological aspects of spatial variation of rye (Secale cereale) yields within Polesia and the Forest-Steppe zone of Ukraine: The usage of geographically weighted principal components analysis. Biosyst Divers 26(4): 276-285. https://doi. org/10.15421/011842.

Kunah OM, Zelenko YV, Fedushko MP, Babchenko AV, Sirovatko, VO, Zhukov OV. 2019. The temporal dynamics of readily available soil moisture for plants in the technosols of the Nikopol Manganese Ore Basin. Biosyst Divers 27(2): 156-162. https://doi. org/10.15421/011921.

Leng G, Huang M. 2017. Crop yield response to climate change varies with crop spatial distribution pattern. Sci Rep 7: 1463. https://doi. org/10.1038/s41598-017-01599-2.

Lesk C, Rowhani P, Ramankutty N. 2016. Influence of extreme weather disasters on global crop production. Nature 529(7584): 84-87. https://doi.org/10.1038/nature16467.

Lioubimtseva E, Henebry G. 2012. Grain production trends in Russia, Ukraine and Kazakhstan: New opportunities in an increasingly unstable world? Front Earth Sci 6(2): 157-66. https://doi.org/ 10.1007/s11707-012-0318-y.

Lobell DB, Schlenker W, Costa-Roberts J. 2011. Climate trends and global crop production since 1980. Science 333: 616-620. https:// doi.org/10.1126/science.1204531.

Melnyk A, Akuaku J, Makarchuk A. 2018. State and prospects of sunflower production in Ukraine. Agrofor 2. https://doi.org/ 10.7251/AGRENG1703116M.

Morgounov A, Haun S, Lang L, Martynov S, Sonder K. 2013. Climate change at winter wheat breeding sites in central Asia, eastern Europe, and USA, and implications for breeding. Euphytica 194 (2): 277-92. https://doi.org/10.1007/s10681-013-0968-1.

Nelson GC, Valin H, Sands RD, Havlík P, Ahammad H, et al. 2014. Climate change effects on agriculture: Economic responses to biophysical shocks. Proc Nat Acad Sci 111(9): 3274-3279. https://doi.org/10.1073/pnas.1222465110.

Osman D, Ozgur A, Ozlem I. 2014. A Methodology to Implement Box-Cox Transformation When No Covariate is Available. Commun Stat-Simul Comput 43: 1740-1759. https://doi.org/ 10.1080/03610918.2012.744042.

Pakhomov OY, Kunakh OM, Babchenko AV, et al. 2019. Temperature effect on the temporal dynamic of terrestrial invertebrates in technosols formed after reclamation at a post-mining site in 
Ukrainian steppe drylands. Biosyst Divers 27(4): 322-328. https://doi.org/10.15421/011942.

Paixão J, Casaroli D, Battisti R, Pêgo EJ, Mesquita M. 2020. Characterizing Sugarcane Production Areas Using Actual Yield and Edaphoclimatic Condition Data for the State of Goiás, Brazil. Int J Plant Prod. https://doi.org/10.1007/s42106-02000101-9.

Radanielson AM, Lecoeur J, Christophe A, Guilioni L. 2012. Use of water extraction variability to screen for sunflower genotypes well adapted to soil water limitation. Funct Plant Biol 39(12): 9991008.

Ray DK, Ramankutty N, Mueller ND, West PC, Foley JA. 2012. Recent patterns of crop yield growth and stagnation. Nat Commun 3: 1293. https://doi.org/10.1038/ncomms2296.

R Core Team. 2018. R: A language and environment for statistical computing. Vienna, Austria: R Foundation for Statistical Computing. https://www.R-project.org/.

Ritz C, Baty F, Streibig JC, Gerhard D. 2015. Dose-Response Analysis Using R. PLoS ONE 10(12): e0146021. https://doi.org/ 10.1371/journal.pone.0146021.

Rodrigues MS, Corá JE, Fernandes C. 2012. Spatial relationships between soil attributes and corn yield in no-tillage system. Revista Brasileira de Ciência do Solo 36(2): 599-609. https://doi.org/ 10.1590/S0100-06832012000200029.

Ryabko D, Hutter M. 2008. Predicting non-stationary processes. Appl Math Lett 21(5): 477-482. https://doi.org/10.1016/j. aml.2007.04.004.

Schär C, Frei C, Lüthi D, Davies HC. 1996. Surrogate climate-change scenarios for regional climate models. Geophys Res Lett 23(6): 669-672. https://doi.org/10.1029/96GL00265.

Schlenker W, Roberts MJ. 2009. Nonlinear temperature effects indicate severe damages to U.S. crop yields under climate change. Proc Nat Acad Sci 106(37): 15594-98. https://doi.org/10.1073/ pnas.0906865106.

Sys C, Van Ranst E, Debaveye J. 1991. Land evaluation. Part 1. Principles in land evaluation and crop production calculations. General Administration for Development Cooperation. Brussels, Belgium: Agricultural Publication.

Thomaz GL, Zagonel J, Colasante LO, Nogueira RR. 2012. Yield of sunflower and oil seed content as a function of air temperature, rainfall and solar radiation. Cienc Rural 42(8): 1380-1385. https://doi.org/10.1590/S0103-84782012000800008.

Ureta C, González EJ, Espinosa A, Trueba A, Piñeyro-Nelson A, Álvarez-Buylla ER. 2019. Maize yield in Mexico under climate change. Agric Syst 177: 102697. https://doi.org/10.1016/j. agsy.2019.102697.

USDA (United States Department of Agriculture). 2017. Production, supply, and distribution (PSD) reports - Oilseeds. https://apps.fas. usda.gov/psdonline/app/index.html\#/app/downloads?tabName= default.

Xiao DP, Moiwo JP, Tao FL, et al. 2015. Spatiotemporal variability of winter wheat phenology in response to weather and climate variability in China. Mitig Adapt Strategies Global Change 20(7): 1191-1202. https://doi.org/10.1007/s11027-013-9531-6.

Zhukov OV, Pelina TO, Demchuk OM, Demchuk NI, Koberniuk SO. 2018. Agroecological and agroeconomic aspects of the grain and grain legumes (pulses) yield dynamic within the Dnipropetrovsk region (period 1966-2016). Biosyst Divers 26(2): 170-176. https://doi.org/10.15421/011826.

Zhygailo OL, Zhygailo TS. 2016. Evaluation of climate change influence on agroclimatic conditions of sunflower growing in Ukraine. Ukr Hydrometeorol J 17: 86-92. https://doi.org/ 10.31481/uhmj.17.2016.10 (in Ukrainian).

Zymaroieva A, Zhukov O, Romanchuck L, Pinkin A. 2019. Spatiotemporal dynamics of cereals grains and grain legumes yield in Ukraine. Bulg J Agric Sci 25(6): 1107-1113.

Zymaroieva A, Zhukov O. 2020. Analyzing cereal and grain legumes (pulses) yields patterns in the forest and forest-steppe zones of Ukraine using geographically weighted principal components analysis. Acta Agric Slov 116(2): 287-297. https://doi.org/ 10.14720/aas.2020.116.2.873.

Zymaroieva A, Zhukov O, Fedonyuk T, Pinkina T. 2020a. The spatiotemporal trend of rapeseed yields in Ukraine as a marker of agroeconomic factors influence. Agron Res 18(S2): 1584-1596. https://doi.org/10.15159/ar.20.119.

Zymaroieva A, Zhukov O, Romanchuck L. 2020b. The spatial patterns of long-term temporal trends in yields of soybean (Glycine max (L.) Merril) in the Central European Mixed Forests (Polissya) and East European Forest Steppe ecoregions within Ukraine. J Cent Eur Agric 21(2): 320-332. https://doi.org/10.5513/JCEA01/21.2.2402.

Cite this article as: Zymaroieva A, Zhukov O, Fedoniuk T, Pinkina T, Vlasiuk V. 2021. Edaphoclimatic factors determining sunflower yields spatiotemporal dynamics in northern Ukraine. OCL 28: 26. 